\title{
Early Serratus Plane Block for Rib Fracture Management Could Avoid Intensive Care Unit Admission
}

\author{
Keywords: Intensive care unit, Regional anesthesia, Serratus plane block. \\ Indian Journal of Critical Care Medicine (2020): 10.5005/jp-journals-10071-23631
}

Mahul Gorecha ${ }^{1}$, Anitha Menon ${ }^{2}$, Emily Woodford ${ }^{3}$, Shuker Yahia ${ }^{4}$, Kalimuthu Marimuthu ${ }^{5}$

Editor,

Rib fractures are a very common chest trauma injury presenting in at least $10 \%$ of injured patients. However, they are associated with significant morbidity, and patients frequently require admission to the intensive care unit (ICU) with mortality rates as high as $33 \%$. ${ }^{1}$ Multimodal analgesia is vital to ensure adequate pain relief enabling patients to breath adequately and mobilize, with regional analgesia becoming the gold standard of pain relief. The newer serratus plane block is a viable alternative to thoracic epidural and paravertebral blockade, where local anaesthetic is deposited either superficial or deep underneath serratus anterior, ${ }^{2}$ with the added benefit of avoiding any motor block while allowing patients to mobilize. It has been shown to be an effective method of pain control, improving incentive spirometry, and allowing an effective cough in patients with rib fractures. ${ }^{3,4}$ Another advantage is that these blocks have the flexibility to be employed in a wide variety of circumstances, where central neuraxial blocks may not be feasible, such as anticoagulated patients, patients with vertebral fractures, and situations with limited positioning options. ${ }^{5}$

We conducted an audit at our hospital looking at rib fracture management over a 21-month period from February 2018 to November 2019, as this was when the rib fracture service was first introduced. During this period, 17 patients were identified, the average age of the patient was 60 years, and average number of fractured ribs were 3 . Their pain was significant enough to need an acute pain referral, and a serratus plane catheter was inserted in addition to multimodal oral analgesia and intermittent boluses were given through the catheter twice a day. Post-procedure, a significant reduction in pain scores were observed, and patients were able to comfortably mobilize, and any morphine PCA's that were running were discontinued. Our hospital has a dedicated consultant delivered pain service that liaises closely with the surgical team to ensure that the majority of nerve blocks are carried out on the day of admission or the following day. Out of all the patients who received a serratus plane block catheter for rib fracture management, the average hospital length of stay was 4 days, and nobody developed any rib fracture complications requiring ITU admission for level 2 or level 3 treatment.

Rib fracture pain is often very difficult to treat, and optimal pain relief needs to be provided early. These patients are often elderly, have multiple coexisting comorbidities, and are on extensive medication of which one is usually an anticoagulant. If pain is not controlled, they will rapidly develop rib fracture-related
${ }^{1}$ Department of Anesthesia, George Eliot Hospital NHS Trust, Nuneaton, UK

${ }^{2-5}$ Department of General Surgery, George Eliot Hospital NHS Trust, Nuneaton, UK

Corresponding Author: Mahul Gorecha, Department of Anesthesia, George Eliot Hospital NHSTrust, Nuneaton, UK, Phone:+447828693782, e-mail: mahul.gorecha@geh.nhs.uk

How to cite this article: Gorecha M, Menon A, Woodford E, Yahia S, Marimuthu K. Early Serratus Plane Block for Rib Fracture Management Could Avoid Intensive Care Unit Admission. Indian J Crit Care Med 2020;24(10):995.

Source of support: Nil

Conflict of interest: None

complications such as pneumonia and respiratory failure. This situation will usually require ICU admission, where the course could potentially be long, costly, and devastating. Our hospital data have shown that an early serratus plane block catheter is a simple intervention that provides excellent analgesia, allows patient mobilization, improves ventilatory mechanics, shortens hospital length of stay, and avoids ICU admission representing a significant cost saving to the hospital, and this strategy should be employed worldwide.

\section{References}

1. May L, Hillermann C, Patil S. Rib fracture management. BJA Education 2016;16(1):26-32. DOI: 10.1093/bjaceaccp/mkv011.

2. Blanco R, Parras T, McDonnell JG, Prats-Galino A. Serratus plane block: a novel ultrasound-guided thoracic wall nerve block. Anaesthesia 2013;68(11):1107-1113. DOI: 10.1111/anae.12344.

3. Martinez T, Belveyre T, Lopez A, Dunyach C, Bouzit Z, Dubreuil G, et al. Serratus plane block is effective for pain control in patients with blunt chest trauma: a case series. Pain Pract 2020;20(2):197-203. DOI: 10.1111/papr.12833.

4. Hernandez N, de Haan J, Clendenin D, Meyer DE, Ghebremichael S, Artime $C$, et al. Impact of serratus plane block on pain scores and incentive spirometry volumes after chest trauma. Local Reg Anesth 2019;12:59-66. DOI: 10.2147/LRA.S207791.

5. Thiruvenkatarajan V, Cruz Eng H, Adhikary SD. An update on regional analgesia for rib fractures. Curr Opin Anaesthesiol 2018;31(5):601-607. DOI: 10.1097/ACO.0000000000000637.

(0) The Author(s). 2020 Open Access This article is distributed under the terms of the Creative Commons Attribution 4.0 International License (https://creativecommons. org/licenses/by-nc/4.0/), which permits unrestricted use, distribution, and non-commercial reproduction in any medium, provided you give appropriate credit to the original author(s) and the source, provide a link to the Creative Commons license, and indicate if changes were made. The Creative Commons Public Domain Dedication waiver (http://creativecommons.org/publicdomain/zero/1.0/) applies to the data made available in this article, unless otherwise stated. 